\title{
Outbreak of Carbapenem-Resistant Acinetobacter baumannii Producing the Carbapenemase OXA-58 in Turkey
}

\author{
Nevgun Ozen ${ }^{1}$, Ayla Ergani ${ }^{2,3}$, Thierry Naas ${ }^{*}, 2$, Dilara Öğünç ${ }^{1}$, Meral Gültekin $^{1}$, Dilek Colak $^{1}$ and \\ Patrice Nordmann ${ }^{2}$ \\ ${ }^{I}$ Medical Microbiology Department, Akdeniz University School of Medicine, Antalya, Turkey \\ ${ }^{2}$ Service de Bactériologie-Virologie, INSERM U914: Emerging Resistance to Antibiotics, Hôpital de Bicêtre, Assistance \\ Publique - Hôpitaux de Paris, Université Paris-11, K.-Bicêtre, Paris, France \\ ${ }^{3}$ Present address: Service de Bactériologie, Hôpital Hôtel Dieu, Assistance Publique - Hôpitaux de Paris, Université \\ Paris-5, Paris, France
}

\begin{abstract}
The use of carbapenems to eradicate multi-drug resistant (MDR) Acinetobacter baumannii may become compromised by the spread of carbapenem-hydrolyzing class D $\beta$-lactamase (CHDL) genes (OXA-23, OXA-40, or OXA-58). Here, we describe the phenotypical and genotypical characterization of MDR A. baumannii isolates, recovered between June and November 2003 in a tertiary-care hospital in Antalya, Turkey.

Hundred and sixteen MDR A. baumannii isolates were isolated from 23 patients, mostly from respiratory samples and from 11 environmental samples. These MDR isolates, belonged to a single clone and remained susceptible to colistin and rifampin only. They produced CHDL OXA-58. In addition, they were also positive for the $b l a_{\text {OXA-51 }}$, for a novel $b l a_{\text {AMPC }}$ (ADC-43) gene and for ISAba1. The bla $a_{\mathrm{OXA}-58}$ gene was located onto a non self-transferable 50-kb plasmid that could be electroporated to A. baumannii 7010 reference strain. One isogenic carbapenem-susceptible strain lost its plasmid carrying $b l a_{\text {OXA-58 }}$ gene. PCR mapping identified similar genetic structures surrounding the $b l a_{\text {OXA-58 }}$ gene as for the prototype $b l a_{\mathrm{OXA}-58}$ gene, e.g. two ISAba3-like insertion sequences bracketing $b l a_{\mathrm{OXA}-58}$ gene.
\end{abstract}

This is the first molecular description of an outbreak of OXA-58- producing A. baumannii isolates in Turkey, further underlining the global spread of such carbapenemase- producing strains in the Mediterranean area.

Keywords: OXA-58, A. baumannii, outbreak, carbapenem resistance, Turkey.

\section{INTRODUCTION}

Imipenem and meropenem are among the drugs of choice for treating nosocomial infections due to multidrug-resistant A. baumannii $[1,2]$. However, their efficacy is being increasingly compromised and carbapenem-resistant isolates are becoming widespread in several regions of the world [35]. A large variety of molecular mechanisms for resistance to carbapenems have been reported in A. baumannii, i.e. acquisition of carbapenem-hydrolyzing $\beta$-lactamases of molecular Ambler class B (metallo-enzymes) and mostly of class D enzymes (oxacillinases) but also rare mutations in genes coding for penicillin-binding proteins and decreased outer membrane permeability [5-8]. Whereas class B enzymes found are of IMP and VIM types in A. baumannii [6], the acquired carbapenem-hydrolyzing class D $\beta$-lactamases (CHDL) are members of three subgroups of enzymes: the OXA-23-, OXA-24/40- and OXA-58- enzymes [3, 6]. OXA58 shares less than $50 \%$ amino acid identity with the two other CHDL groups, which share $60 \%$ amino acid sequence

*Address correspondence to this author at the Service de BactériologieVirologie, Hôpital de Bicêtre, 78 rue du Général Leclerc, 94275 K.-Bicêtre Cedex, France; Tel: 33-1-45-21-29-86; Fax: 33-1-45-21-63-40;

E-mail: thierry.naas@bct.ap- hop-paris.fr identity $[6,9]$. Recently, a fourth subgroup of OXA $\beta$ lactamases sharing less than $63 \%$ amino acid identity with subgroups 1 and 2 has been identified [10,11]. These enzymes (OXA-51 or 69-like) correspond to naturallyoccurring oxacillinases of A. baumannii and it is likely that their overexpression associated with a degree of outer membrane permeability defect may explain partially carbapenemresistance in A. baumannii [11-13].

Outbreaks of OXA-23 or OXA-40-producing A. baumannii have been increasingly reported worldwide [3]. $\beta$ Lactamase OXA-58 was first identified in France from a carbapenem-resistant A. baumannii isolate recovered in 2003 that was at the origin of an outbreak $[9,14]$. This $b l a_{\text {OXA-58 }}$ gene was plasmid-located. Since then, the $b l a_{\text {OXA-58 }}$ gene has been identified worldwide $[15,16]$ and several outbreaks have been documented [17-21]. Genetic studies showed that the gene was bracketed by insertion sequences likely at the origin of its acquisition and its expression [22].

The aim of this study was to analyze the molecular mechanisms of carbapenem resistance in A. baumannii isolates identified at the university hospital of Antalya, Turkey. 


\section{MATERIALS AND METHODOLOGY}

\section{Hospital Setting, Outbreak and Surveillance}

Akdeniz University Hospital is a 746-bed tertiary-care teaching hospital with four ICUs totalizing 90 beds. The outbreak occurred on the fourth ICU with 12 beds and 4 single rooms. After the first isolation of MDR A. baumannii from the tracheal aspirate of a patient in the ICU in May 2003, a prospective surveillance study was initiated in order to determine the epidemiology of MDR A. baumannii, and infection control measures were strengthened according to the recommendations of Centres for Disease Control and Prevention by the Infection Control Committee of the hospital [23]. After the first isolation of MDR A. baumannii, a screening programme was initiated. Samples were taken once a week from all patients hospitalized in the ICU and for all newly admitted patients as well as the environmental cultures. Environmental sampling included: (i) swabs taken from the patient's direct environment including medical devices; (ii) swabs from handwashing sinks; and (iii) fintertips of healthcare workers. Samples were taken using cottontipped swabs moistened with sterile saline. Swabs, rinsing fluid and fingertips of healthcare workers were cultured on antibiotic-supplemented (imipenem $2 \mu \mathrm{g} / \mathrm{ml}$ ) and standard MacConkey agar plates and incubated aerobically at $37^{\circ} \mathrm{C}$ for up to $48 \mathrm{~h}$. In addition to contact precautions, stringent compliance with standard precautions, especially the use of alcohol-based hand-rub solutions, was strongly recommended for all patients in the ward regardless of their bacteriological status. Active surveillance was continued until three months after the last colonized patient was discharged. Thus in March 2004, the epidemic was officially considered over and the surveillance programme returned to a normal operation level (Fig. 1).

\section{Bacterial Strains Antimicrobial Agents and MIC Determinations}

A. baumannii isolates was identified by means of a commercial identification gallery (API 32GN system, BioMérieux, Marcy-l'Etoile, France). Identification of $A$. baumannii isolates was confirmed by detection and sequencing of the intrinsic bla $_{\text {oxa-51/69-like gene [24]. A. baumannii MAD [9], A. bauman- }}$ nii Gr-1 [19], A. baumannii Ank-1 and A. baumannii Ist-1 [15] was used as a reference strains for PCR mappings and PFGE. A. baumannii CIP7010 and Escherichia coli DH10B were used for electroporation, and azide-resistant E. coli J53 or rifampin-resistant A. baumannii CIP7010 for conjugation. E. coli NCTC 50192 harbouring 154-, 66-, 38-, and 7-kb plasmids was used as a plasmid-containing reference strain [17].

Antimicrobial susceptibility testing was determined by disk diffusion method using interpretative criteria of the Clinical and Laboratory Standard Institute (CLSI) [25]. MICs of the different antibiotics were determined by E-test (AB Biodisk, Solna, Sweden) according to manufacturer's instructions and interpreted according to CLSI, and Eucast for colistin and tigecyclin.

\section{PFGE}

Pulsed-field gel electrophoresis (PFGE) was performed with ApaI-restricted whole-cell DNAs embedded in $1 \%$ agarose plugs and separated in a $1 \%$ pulsed field-certified agarose gel using a contour-clamped homogeneous electric field DRII system (Bio-Rad, Marnes-La-Coquette, France), as previously described [26]. PFGE results were analysed by eye according to the criteria of Tenover et al. [27].

\section{Plasmid Content, Electroporation and Mating Out Experiments}

Direct transfer of resistance into azide-resistant $E$. coli J53 or to rifampin-resistant A. baumannii CIP7010 (MIC $>256 \mu \mathrm{g} / \mathrm{mL}$ ) was attempted as previously reported [17]. Extraction of plasmid DNA from A. baumannii isolates was attempted using the Kieser extraction method [28]. Plasmid extracts were analyzed by electrophoresis on a \% 0,7 agarose gel [9]. Extracted plasmids were electroporated into $A$. baumannii CIP7010 and E. coli DH10B strains using a Gene Pulser II electroporator (Bio-Rad, Ivry-sur-Seine, France). Electroporants were selected on ticarcillin $(50 \mu \mathrm{g} / \mathrm{ml})$ containing TSA plates.

\section{Isoelectric Focusing (IEF) Analyses and Biochemical Properties}

Crude $\beta$-lactamase extracts were obtained from $10-\mathrm{ml}$ cultures of $A$. baumannii and analytical isoelectric focusing

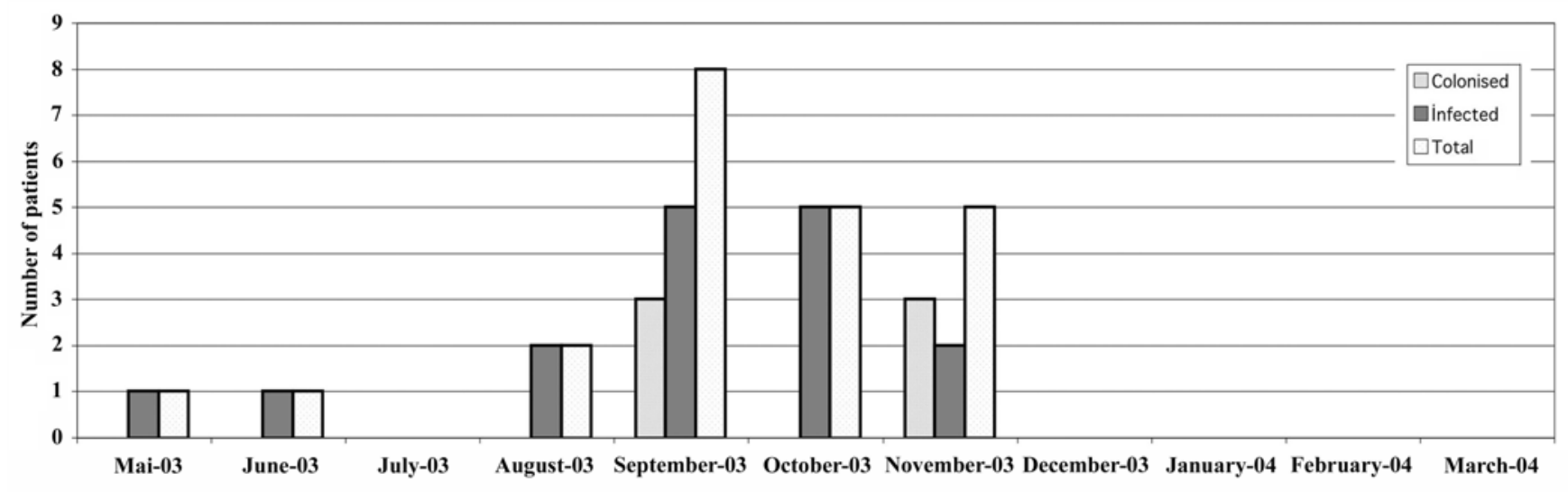

Fig. (1). Epidemic curve. 
(IEF) was performed with an ampholine polyacrylamide gel, as described previously [17]. The specific carbapenem hydrolysis was measured as described [17].

\section{PCR Analyses and Sequencing}

Genomic DNA extraction and PCR experiments were performed as previously described $[17,26]$. The PCR amplification and the primers used to search for known $\beta$ lactamase genes of Ambler class B and D carbapenemases were sought by PCR with primers specific for the $b l a_{\mathrm{IMP}}$, bla $_{\mathrm{VIM}}$, bla $_{\mathrm{KPC}}, b l a_{\mathrm{OXA}-23}-\mathrm{like}, b a_{\mathrm{OXA}-40}-\mathrm{like}$, and $b l a_{\mathrm{OXA}-58}$ genes and for Ambler class A bla $a_{\mathrm{TEM}}, b l a_{\mathrm{SHV}}, b l a_{\mathrm{PER}-1 / 2}$, bla $_{\mathrm{VEB}-1}, b l a_{\mathrm{GES}-1}$ and bla $_{\mathrm{CTX- \textrm {M }}}$ in $A$. baumannii isolates have been described previously $[17,26]$. Detection of the $b l a_{\mathrm{AmpC}^{-}}$ type and bla $_{\text {OXA-69 }}$ genes of $A$. baumannii was performed with primers listed in Table $\mathbf{1}$ which hybridized to internal parts but also to outer parts of these $\beta$-lactamase genes [17, 26]. The presence of ISAbal inserted upstream of a $b l a_{\mathrm{AmpC}}$ and $b a_{\text {OXA-69-like }} \beta$-lactamase gene were also sought by PCR [12, 29].

For PCR-mapping experiments of the genetic environment of bla $a_{\text {OXA-58, }}, 500 \mathrm{ng}$ of total DNA of A. baumannii isolates were used in standard PCR reaction mixtures $[9,17]$. The PCR primers are listed in Table $\mathbf{1}$ and Fig. (2A). The following amplification program was used: $10 \mathrm{~min}, 94^{\circ} \mathrm{C} ; 35$ cycles of $1 \mathrm{~min}, 94^{\circ} \mathrm{C}, 1 \mathrm{~min}, 55^{\circ} \mathrm{C}, 3-5 \mathrm{~min}, 72^{\circ} \mathrm{C}$; followed by a final extension of $10 \mathrm{~min}$ at $72^{\circ} \mathrm{C}$.
PCR products were purified using QIAquick PCR Purification Kit (Qiagen, Les Ulis France) and subsequently sequenced on both strands on an Applied Biosystem sequencer (ABI 3100, Les Ulis, France). Nucleotide sequence analysis was performed at the National Centre of Biotechnology Information website (http://www.ncbi.nlm.nih.gov).

The nucleotide sequences reported in this paper have been assigned to the GenBank nucleotide database.

\section{RESULTS}

\section{Epidemiology and Surveillance Study of the Carbapenem-} Resistant $A$. baumannii Isolates

The first MDR A. baumannii was isolated from the tracheal aspirate of a patient hospitalized in ICU in May 2003 (Fig. 1). From May until December 2003, at least one colonized patient was always present in the ward. Patient-care equipment and environmental surfaces were also screened for A. baumannii colonization. From January until March 2004 (end of surveillance), no new cases of MDR A. baumannii were diagnosed throughout the ICU (Fig. 1). Between May 2003 and March 2004, a total of 116 A. baumannii isolates were recovered during this outbreak, being 11 environmental samples and 105 clinical samples from 23 patients. Clinical data were analyzed for all 23 patients (Table 2). The ages of the patients ranged from 3 to 75 years (mean age, 36, 5 years). Seventeen patients were infected (74\%) and $6(26 \%)$ were colonized according to guidelines from Centre for Diseases Control and Prevention [23]. Most of the A. baumannii

Table 1. Primers Used in this Study

\begin{tabular}{|c|c|c|c|}
\hline OXA-58A & 1 & CGATCAGAATGTTCAAGCGC & {$[14]$} \\
\hline ISAba2A & 3 & AATCCGAGATAGAGCGGTTC & {$[22]$} \\
\hline ISAba3B & 4 & CGTTTACCCCAAACATAAGC & {$[22]$} \\
\hline MAD-Th & 6 & AACAGCAATAGCCATCAAC & {$[22]$} \\
\hline SM2 & 7 & AAGTGTCTATATTCTCACC & {$[22]$} \\
\hline $\operatorname{Re} 27-2$ & 8 & AACATAATGGCTGTTATACG & {$[22]$} \\
\hline $\operatorname{Re} 27-1$ & 9 & TTCGTATAACCGCCATTATG & {$[22]$} \\
\hline IS Aba-1 B & 13 & AATGATTGGTGACAATGAAG & {$[17,22]$} \\
\hline pre-ABprom+ & 14 & GACCTGCAAAGAAGCGCTGC & {$[17]$} \\
\hline pre-AB 1 & 15 & ACAGAGGAGCTAATCATGCG & [17] \\
\hline pre-AB2 & 16 & GTTCTTTTAAACCATATACC & {$[17]$} \\
\hline oxa-ABint1 & 17 & CGACCGAGTATGTACCTGCTT & {$[17]$} \\
\hline oxa-ABint2 & 18 & CTAAGTTAAGGGAGAACGC & {$[17]$} \\
\hline pre-oxa-69A & 19 & CTAATAATTGATCTACTCAAG & [17] \\
\hline pre-oxa-69B & 20 & CCAGTGGATGGATAGATTATC & {$[17]$} \\
\hline
\end{tabular}


A.

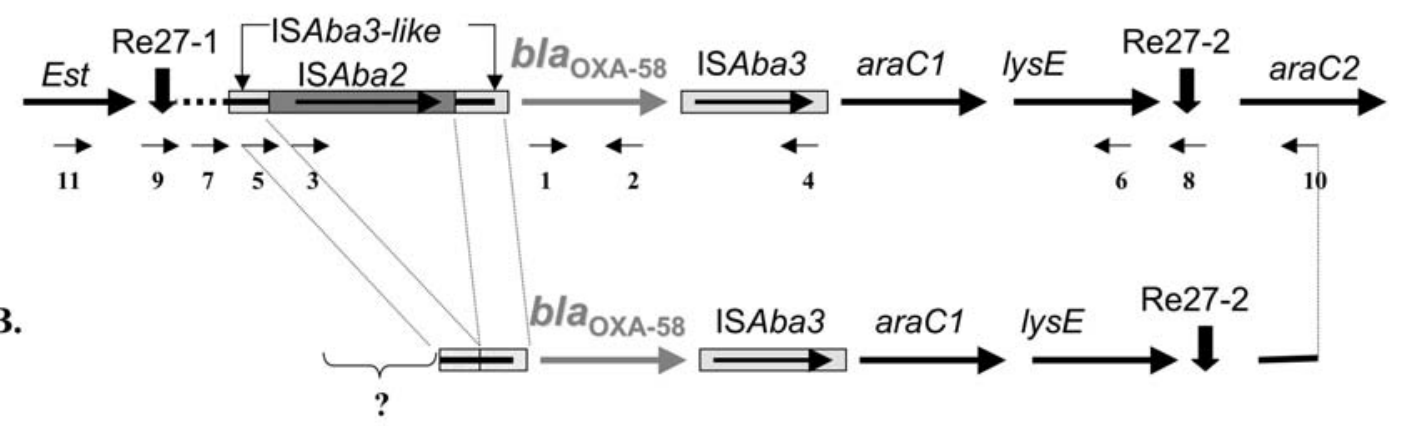

C.

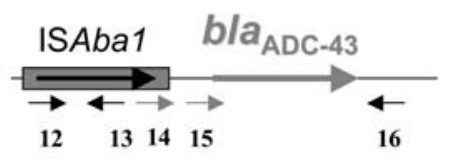

D.

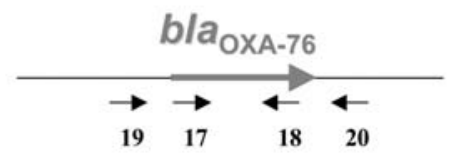

Fig. (2). Schematic map of the genetic structure (A) containing the blaOXA-58 genes found in (A. baumannii MAD [9, 15], (B) that found in A. baumannii 7a (this study), (C) of ISAba 1 insertied in front of $b l a_{\mathrm{ADC}-43}$, and (D) of bla $a_{\mathrm{OXA}-76}$ gene. Genes and their corresponding transcription orientations are indicated by horizontal arrows. The transcription regulator genes ( $\mathrm{raCl}$ and $\operatorname{araC2}$ ), the threonine efflux protein gene $(l y s E)$, the esterase gene (Est), the putative regulatory gene ( $r e g)$, the gene encoding an ORF of unknown function (orf), the putative transposase gene $(\operatorname{tnp} A)$, and the putative resolvase gene (res) are indicated. Vertical arrows are for the Re27-like sequences. The genetic structure which is highly similar between [1] and (2) is indicated with the dotted lines. The primers are indicated under arrows and the number correspond to the table.

were isolated from the respiratory tract (42 respiratory samples from 20 patients) in ICU patients. Environmental samples that were positive for A. baumannii were taken from the ICU unit, consisted of 5 hand cultures from staff, 2 from respiratory devices, 3 from respiratory monitors and 1 from dressing medical devices (Table 3). A. baumannii isolates were resistant to all $\beta$-lactams, including imipenem (MIC: $\geq 32 \mu \mathrm{g} / \mathrm{mL}$ ) and meropenem (MIC: 4 to $>32 \mu \mathrm{g} / \mathrm{mL}$ ), to ciprofloxacin (MIC: $>32 \mu \mathrm{g} / \mathrm{mL}$ ), and to amikacin (MIC: $>256 \mu \mathrm{g} / \mathrm{mL}$ ). Variable susceptibility was found for rifampin (MIC: 4 to $>256 \mu \mathrm{g} / \mathrm{mL}$ ). The isolates were resistant to tigecyclin (MIC: $12 \mu \mathrm{g} / \mathrm{mL}$ ) and borderline susceptible to colistin (MIC: 3 $\mu \mathrm{g} / \mathrm{mL}$ ). Strain 1 isolated from patient 1 (index patient) on the day of his admission showed higher MICs for sulbactam (32 $\mu \mathrm{g} / \mathrm{mL}$ ), meropenem ( $>32 \mu \mathrm{g} / \mathrm{mL}$ ) and imipenem (>32 $\mu \mathrm{g} / \mathrm{mL}$ ). Several strains had variable sulbactam: $8-32 \mu \mathrm{g} / \mathrm{mL}$, imipenem: $4-32 \mu \mathrm{g} / \mathrm{mL}$ meropenem: $8-32 \mu \mathrm{g} / \mathrm{mL}$ and tazobactam: $32-256 \mu \mathrm{g} / \mathrm{mL}$ susceptibility suggesting that resistant strains even though clonally-related might exhibit different pattern of resistance. While not yet fully understood, this phenomenon was already reported in A. baumannii [17]. It is tempting to suggest that rearrangements in plasmids and/or modification in outer membrane proteins (OMPs) could account for the different MIC values. By contrast two strains (7a and $7 \mathrm{~b}$ ) were isolated the same day from patient 7 , differing only by the imipenem-resistance; strain $7 \mathrm{~b}$ being susceptible both to imipenem (MIC: $4 \mu \mathrm{g} / \mathrm{mL}$ ) and to meropenem (MIC: $\underline{4}$ $\mu \mathrm{g} / \mathrm{mL}$ ) (Table 2).

\section{PCR Analysis, IEF and Carbapenem Hydrolysis}

One A. baumannii isolate per patient, except for patient 7 where two strains were retained, and 2 environmental isolates were further investigated. These A. baumannii isolates were positive for $b l a_{\mathrm{OXA}-58}$-like and the chromosomallylocated $b l a_{\mathrm{OXA}-51}$-like and $b l a_{\mathrm{AMPC}}$ genes. The carbapenemsusceptible strain $7 \mathrm{~b}$ was positive only for $b l a_{\mathrm{OXA}-51}$-like and for $b l a_{\mathrm{AMPC}}$ genes. Significant carbapenem-hydrolysis was found for all isolates except for strain $7 \mathrm{~b}$. Isoelectricfocusing confirmed the expression of OXA-58 (pI 7.0) and AmpC (pI > 8.5) (data not shown). Sequencing of the amplified fragments confirmed the presence of these genes and showed that the $b l a_{\text {OXA-58 }}$ gene was identical to that of the prototype OXA-58 $\beta$-lactamase described in Toulouse [9] and of other southern European regions $[15,19,20]$, thus underscoring the wide geographical spread of this gene. Sequencing of bla $a_{\text {OXA-51-like gene revealed the presence of }}$ the bla OXA-76 gene previously described in A. baumannii isolates from different regions (Spain, Turkey, Hong Kong and Singapore) [10]. 
Table 2. Case History of ICU Patients with OXA-58-Producing A. baumannii.

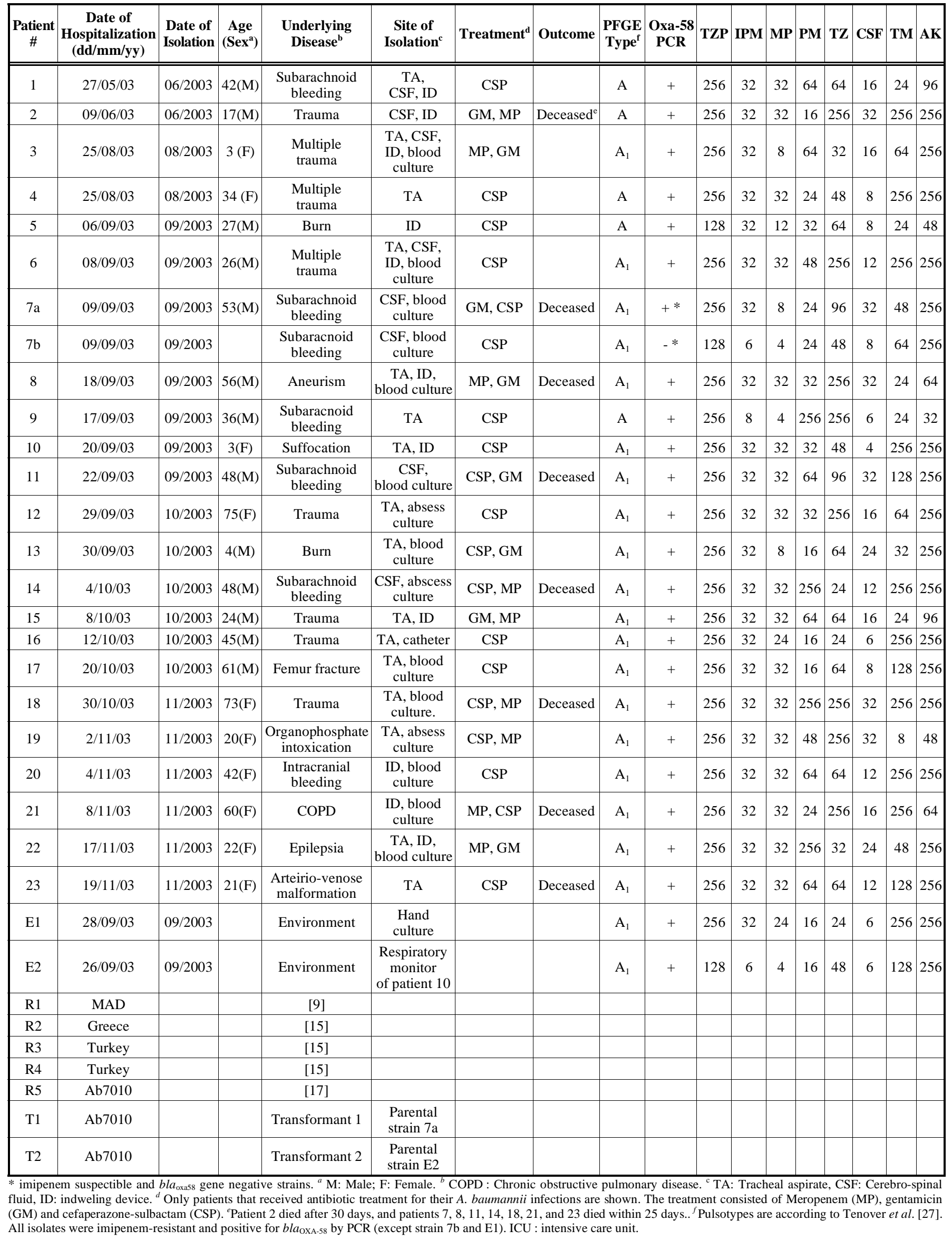


Sequencing of $b l a_{\mathrm{AmpC}}$ gene and deduction of its amino acid sequence revealed two changes (E322V; N341S) with the mobilized version of A. baumannii AMPC, aba-1 found in Oligella urethalis AMPC [30]. The sequence was assigned theADC number ADC-43. The closest $b l a_{\mathrm{AmpC}}$ was bla $_{\mathrm{ADC}-7}$ gene, with $98 \%$ similarity (16 nucleotide leading to 5 amino acid changes). ISAbal was found in A. baumannii inserted upstream of $b l a_{\mathrm{AMPC}}$ genes [31].

\section{Genetic Environment}

PCR mapping showed that upstream of $b l a_{\text {OXA-58, an }}$ ISAba3-like element was found, that was not truncated by IS26, ISAba1 or ISAba2 elements as already described. In fact, PCR experiments failed to amplify the entire IS element, suggesting that the element might be truncated at its 5 '-extremity, as already described [22] (Fig. 2). Downstream of the $b l a_{\text {OXA-58 }}$ gene, an entire copy of ISAba3 was identified, followed by the araCl and $l y s E$ genes, as observed in natural plasmid pMAD [22]. Downstream of the lys $E$ gene, a sequence similar to what has been defined as the $\operatorname{Re} 27-2$ structure in A. baumannii MAD was identified. This structure has been proposed to be at the origin of the acquisition of the bla $a_{\text {OXA-58 }}$ gene in that latter strain [22]. Then, an araC2-like gene was identified as found in A. baumannii MAD (Fig. 2). Downstream of $\operatorname{araC2}$, a gene encoding a putative regulator was found, followed by an orf corresponding to a putative 160 amino-acid long protein, followed by a gene encoding a putative transposase.

Table 3. Environmental Sampling

\begin{tabular}{|c|c|c|c|}
\hline $\begin{array}{c}\text { Environmental } \\
\text { Samples }\end{array}$ & $\begin{array}{c}\text { Total } \\
\text { Sample }\end{array}$ & A. baumannii & Oxa 58 PCR \\
\hline \hline Hand culture & 19 & 5 & $+*$ \\
\hline Monitor & 4 & 3 & + \\
\hline Dressing medical device & 3 & 1 & + \\
\hline Respiratory devices & 4 & 2 & - \\
\hline Stethoscope & 2 & - & - \\
\hline Infusion pump & 1 & - & - \\
\hline Sinks (Handwashing) & 2 & - & + \\
\hline
\end{tabular}

\section{Genetic Location}

In line with previous findings $[9,22]$, the $b l a_{\text {OXA-58 }}$ gene was plasmid mediated. In all carbapenem-resistant isolates, a 50-kb plasmid was present but it was not self-transferable to rifampin-resistant $A$. baumannii strain. Electroporation with isolated plasmid into A. baumannii CIP7010 revealed that the $b l a_{\text {OXA-58 }}$ gene was identified in those electroporants, but not in E. coli. Heritier et al. [32] demonstrated that OXA-58 has a weak carbapenemase activity and plays a role in carbapenem resistance in $A$. baumannii, particularly when highly expressed. MICs of transconjugants were identical to those already obtained with natural plasmid pMAD expressing OXA-58 (data not shown).

\section{PFGE Analysis}

The carbapenem-resistant A. baumannii isolates gave similar PFGE patterns (Fig. 3), differing by only three bands for some isolates. The imipenem-susceptible $7 \mathrm{~b}$ isolate from patient 7 showed the same PFGE pattern as the carbapenemresistant 7 a strains (Fig. 3), but was lacking bla $a_{\text {OXA-58. This }}$ observation confirms, as recently suggested by Bogearts et al. [17], that OXA-58-producing A. baumannii isolates may occasionally loose the $b l a_{\text {OXA-58 }}$ gene and its surrounding genetic structure in the absence of carbapenem selection pressure. No plasmid could be evidenced in that isolate, suggesting that the entire plasmid containing $b l a_{\text {OXA-58 }}$ gene was lost. The $b l a_{\text {OXA-76 }}$ gene was however detected by PCR in that strain, further suggesting that these $\beta$-lactamase genes may be present in carbapenem-susceptible strains as shown by Héritier et al. [10].

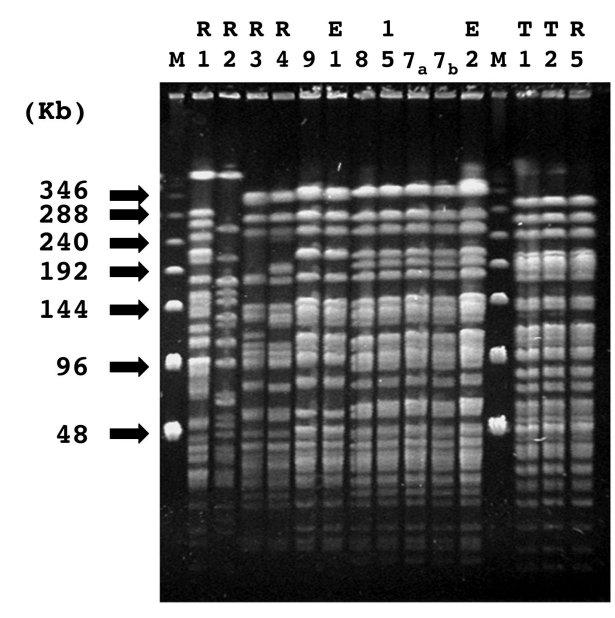

Fig. (3). PFGE patterns of $A$. baumannii isolates. The assigned numbers of A. baumannii isolates are shown over the lanes of the gel and correspond to those of Table 2 . The positions of molecular size markers in kilobases (M) are shown on the left side of the gel.

Very recently, A. baumannii OXA-58 isolates have been described in Greece and in Turkey $[15,22]$. When the isolates of Antalya were compared to these strains, a genetic relationship could be established with the Turkish isolates but not with the Greek strain, suggesting that a single clone can be found in several regions of Turkey (Fig. 3) [22].

\section{DISCUSSION}

Infections with A. baumannii are of great concern for hospitalized patients, showing the highest individual rate of incidence, particularly, in the intensive care units [3]. MDR A. baumannii clones are spreading throughout many different geographic areas [20] and treatment options for MDR $A$. baumannii infections are limited in most cases to carbapenems. The emergence of imipenem resistance means that 
sulbactam, colistin and perhaps tigecyclin may be the only therapeutic options for treating infections caused by these strains. The high level of resistance to imipenem in A. baumannii clinical isolates and the clinical risk factors favouring the acquisition of imipenem-resistant $A$. baumannii have been reported previously [3, 4]. Although carbapenem resistance may be caused, in part by impaired permeability, resulting from decreased expression of porins, or by modifications in penicillin-binding proteins $[3,6]$, most recent reports have indicated that carbapenem-hydrolysing $\beta$-lactamases especially the OXA-types play a major role [32].

After the initial report in Toulouse, France [9], OXA-58producing A. baumannii isolates have been reported in several countries around the world suggesting a wide distribution $[15,16]$. In Europe, they have been reported in Greece, Italy, Turkey, Spain, and Belgium [15, 16, 22]. Hospitals outbreaks have been so far documented in France, Belgium, Italy, Greece and in Tunisia [17-21]. In Belgium, the isolation was subsequent of a patient transfer from Greece [17]. This is the first description of an outbreak of OXA-58 producing A. baumannii isolates in Turkey. Importantly, the fact that a large outbreak arose in the hospital despite early implementation of appropriate barrier precautions underlines the epidemic potential of such resistant strains.

This bacterial species naturally produces a chromosomally-encoded cephalosporinase that may be overexpressed due to insertion of ISAbal, which brings promoter sequences necessary for high-level expression of this $\beta$ lactamase [29]. As observed for the other carbapenemhydrolyzing oxacillinase genes, bla $_{\text {OXA-58 }}$ was not present in the form of a gene cassette in a class 1 integron, a situation that contrasts to that found for most of the oxacillinase genes. The genetic structures surrounding the $b l a_{\mathrm{OXA}-58}$ gene were similar to those identified in association with the $b l a_{\mathrm{OXA}-58}$ gene in a series of isolates identified from France, Italy or Greece [22], indicating that a common structure has been at the origin of the dissemination of these genes. In addition, the IS element located upstream of $b l a_{\text {OXA-58 }}$ gene has been suggested to be responsible of high level expression by providing strong promoter sequences [22]. Furthermore, our study evidenced that $b l a_{\text {OXA-58 }}$-positive plasmids might be lost suggesting a genetic instability of these $A$ baumannii specific plasmids.

Contaminated hands and gloves of the ward staff seem to have an important role in patient-to patient transmission of A. baumannii [1, 2, 3, 17]. In our study, $25 \%$ of the samples collected from hands of ICU personnel were positive for imipenem-resistant $A$. baumannii. In addition, the detection of a common clone among environmental and clinical imipenem-resistant $A$. baumannii indicates that environmental contamination contributes to the difficulty in restricting spread of this organism in the hospital. This outbreak was restricted to only one ICU because the four ICUs are independent and geographically separated from each other, with dedicated nursing and medical staffs. Furthermore, patient transfer between the ICUs were rare and during the epidemic period were totally restricted. Surveillance cultures and strict antiseptic techniques possibly reduced the further spread of these bacteria.

This report constitutes the first report of a nosocomial dissemination of an OXA-58 producing A. baumannii strain in Turkey, after identification single OXA-58-producing $A$. baumannii isolates from this country $[15,33]$. The current worldwide emergence of multiresistant $A$. baumannii isolates is mostly associated to acquisition of carbapenem-resistance determinants. Therefore, carbapenemases seem to be the main cause of carbapenem-resistance in A. baumannii and thus have to be considered as the main target for development of inhibitors. Prospective surveillance programs by characterization of antibiotic resistance, genotyping and plasmid analysis will be useful to follow the recurrence of the described A. baumannii clone as well as to rapidly detect genotype and resistance pattern changes in new emerging clones in our country.

\section{ACKNOWLEDGEMENTS}

$\mathrm{NO}$ and $\mathrm{AE}$ contributed equally to this work. We are grateful to Nicolas Fortineau for helpful discussions. ADC number was kindly assigned by Miriam Barlow. This work was funded by a grant from the Ministère de l'Education Nationale et de la Recherche (UPRES-EA3539), Université Paris Sud, and by the European Community (6th PCRD, LSHM-CT-2005-018705).

\section{REFERENCES}

[1] Bergogne-Bérézin E, Towner KJ. Acinetobacter spp. as nosocomial pathogens: microbiological, clinical and epidemiological features. Clin Microbiol Rev 1996; 9:148-65.

[2] Allen DM, Hartman BJ. Acinetobacter species. In: Mandell GL Bennett JE, Dolin R, Eds. Principles and practice of infectious diseases. 5th ed. Philadelphia, Pa: Churchill Livingstone 2000; 2339-4.

[3] Peleg AY, Seifert H, Paterson DL. Acinetobacter baumannii: emergence of a successful pathogen. Clin Microbiol Rev 2008; 21 : 538-82.

[4] Paterson DL. The epidemiological profile of infections with multi drugresistant Pseudomonas aeruginosa and Acinetobacter species. Clin Infect Dis 2006; 43(Suppl 2): S43-8.

[5] Bonomo RA, Szabo D. Mechanisms of multidrug resistance in Acinetobacter species and Pseudomonas aeruginosa. Clin Infect Dis 2006; 43(Suppl 2): S49-56.

[6] Poirel L, Nordmann P. Carbapenem resistance in Acinetobacter baumannii: mechanisms and epidemiology. Clin Microbiol Infect 2006; 12: 826-36.

[7] Clark RB. Imipenem resistance among Acinetobacter baumannii: association with reduced expression of a 33-36 kDa outer membrane protein. J Antimicrob Chemother 1996; 38: 245-51.

[8] Gehrlein M, Leying H, Cullmann W, Wendt S, Opferkuch W. Imipenem resistance in Acinetobacter baumannii is due to altered penicillin-binding proteins. Chemother 1991; 37: 405-12.

[9] Poirel L, Marque S, Héritier C, Segonds C, Chabanon G, Nordmann P. OXA-58, a novel class D beta-lactamase involved in resistance to carbapenems in Acinetobacter baumannii. Antimicrob Agents Chemother 2005; 49: 202-8.

[10] Héritier C, Poirel L, Fournier PE, Claverie JM, Raoult D, Nordmann P. Characterization of the naturally occurring oxacillinase of Acinetobacter baumannii. Antimicrob Agents Chemother 2005; 49: 4174-9.

[11] Brown S, Young HK, Amyes SGB. Characterisation of OXA-51, a novel class D carbapenemase found in genetically unrelated clinical strains of Acinetobacter baumannii from Argentina. Clin Microbiol Infect 2005; 11: 11-5.

[12] Turton JF, Ward ME, Woodford N, et al. The role of ISAbal in expression of OXA carbapenemase genes in Acinetobacter baumannii. FEMS Microbiol Lett 2006; 258: 72-7.

[13] Fernández-Cuenca F, Martínez-Martínez L, Conejo MC, Ayala JA, Perea EJ, Pascual A. Relationship between $\beta$-lactamase production, outer membrane protein and penicillin-binding protein profiles on the activity of carbapenems against clinical isolates of Acinetobacter baumannii. J Antimicrob Chemother 2003; 51: 565-74.

[14] Héritier C, Dubouix A, Poirel L, Marty N, Nordmann P. A nosocomial outbreak of Acinetobacter baumannii isolates expressing 
the carbapenem-hydrolysing oxacillinase OXA-58. J Antimicrob Chemother 2005; 55: 115-8.

[15] Marqué S, Poirel L, Héritier C, et al. Regional occurrence of plasmid-mediated carbapenem-hydrolyzing oxacillinase OXA-58 in Acinetobacter spp. in Europe. J Clin Microbiol 2005; 43: 48858.

[16] Coelho J, Woodford N, Afzal-Shah M, Livermore D. Occurrence of OXA-58-Like Carbapenemases in Acinetobacter spp. Collected over 10 Years in Three Continents. Antimicrob Agents Chemother 2006; 50: 756-8

[17] Bogaerts P, Naas T, Wybo I, et al. Outbreak of infection by carbapenem-resistant Acinetobacter baumannii producing the carbapenemase OXA-58 in Belgium. J Clin Microbiol 2006; 44: 4189-92.

[18] Pournaras S, Markogiannakis A, Ikonomidis A, et al. Outbreak of multiple clones of imipenem-resistant Acinetobacter baumannii isolates expressing OXA-58 carbapenemase in an intensive care unit. J Antimicrob Chemother 2006; 57: 557-61.

[19] Poirel L, Lebessi E, Héritier C, Patsoura A, Foustoukou M, Nordmann P. Nosocomial spread of OXA-58-positive carbapenemresistant Acinetobacter baumannii isolates in a paediatric hospital in Greece. Clin Microbiol Infect 2006; 12: 1138-44.

[20] Giordano A, Varesi P, Bertini A, et al. Outbreak of Acinetobacter baumannii producing the carbapenem-hydrolyzing oxacillinase OXA-58 in Rome, Italy. Microb Drug Resist 2007; 13: 37-43.

[21] Poirel L, Mansour W, Bouallegue O, Nordmann P. Carbapenemresistant Acinetobacter baumannii isolates from Tunisia producing the OXA-58-like carbapenem-hydrolyzing oxacillinase OXA-97. Antimicrob Agents Chemother 2008; 52: 1613-7.

[22] Poirel L, Nordmann P. Genetic structures at the origin of acquisition and expression of the carbapenem-hydrolyzing oxacillinase gene blaOXA-58 in Acinetobacter baumannii. Antimicrob Agents Chemother 2006; 50: 1442-8.

[23] Siegel JD, Rhinehart E, Jackson M, Chiarello L. Healthcare Infection Control Practices Advisory Committee. Management of multidrug-resistant organisms in health care settings, 2006. Am J Infect Control 2007; 35(Suppl 2): S165-93. 672-82.
[24] Turton JF, Woodford N, Glover J, Yarde S, Kaufmann ME, Pitt TL. Identification of Acinetobacter baumannii by detection of the blaOXA-51-like carbapenemase gene intrinsic to this species. J Clin Microbiol 2006; 44: 2974-6.

[25] Clinical and Laboratory Standards Institute. Performance standards for antimicrobial susceptibility testing; fifteenth informational supplement. M100-S15. Clinical and Laboratory Standards Institute, Wayne, Pa, USA. 2005.

[26] Naas T, Bogaerts P, Bauraing C, Degheldre Y, Glupczynski Y, Nordmann P. Emergence of PER and VEB extended-spectrum beta-lactamases in Acinetobacter baumannii in Belgium. J Antimicrob Chemother 2006; 58: 178-2.

[27] Tenover FC, Arbeit RD, Goering RV, et al. Interpreting chromosomal DNA restriction patterns produced by pulsed-field gel electrophoresis: criteria for bacterial strain typing. J Clin Microbiol 1995; 33: 2233-9.

[28] Kieser T. Factors affecting the isolation of CCC DNA from Streptomyces lividans and Escherichia coli. Plasmid 1984; 12: 19-36.

[29] Heritier C, Poirel L, Nordmann P. Cephalosporinase overexpression resulting from insertion of ISAbal in Acinetobacter baumannii. Clin Microbiol Infect 2006; 12: 123-30.

[30] Mammeri H, Poirel L, Mangeney N, Nordmann P. Chromosomal integration of a cephalosporinase gene from Acinetobacter baumannii into Oligella urethralis as a source of acquired resistance to beta-lactams. Antimicrob Agents Chemother 2003; 47: 1536-42.

[31] Hujer KM, Hamza NS, Hujer AM, et al. Identification of a new allelic variant of the Acinetobacter baumannii cephalosporinase, ADC-7 beta-lactamase: defining a unique family of class $C$ enzymes. Antimicrob Agents Chemother 2005; 49: 2941-8.

[32] Héritier C, Poirel L, Lambert T, Nordmann P. Contribution of acquired carbapenem-hydrolyzing oxacillinases to carbapenem resistance in Acinetobacter baumannii. Antimicrob Agents Chemother 2005; 49: 3198-202.

[33] Vahaboglu H, Budak F, Kasap M, et al. High prevalence of OXA51-type class D beta-lactamases among ceftazidime-resistant clinical isolates of Acinetobacter spp.: co-existence with OXA-58 in multiple centres. J Antimicrob Chemother 2006; 58: 537-42.

(C) Ozen et al.; Licensee Bentham Open.

This is an open access article licensed under the terms of the Creative Commons Attribution Non-Commercial License (http: //creativecommons.org/licenses/by$\mathrm{nc} / 3.0 /$ ) which permits unrestricted, non-commercial use, distribution and reproduction in any medium, provided the work is properly cited. 